\title{
Sanal Flow Choking in Nanoscale Fluid Flow Systems at the Zero Slip Length: Universal Benchmark Data for 3D in Silico, in Vitro and in Vivo Experiments
}

V R Sanal Kumar ( $\nabla$ vr_sanalkumar@yahoo.co.in ) Indian Space Research Organisation

Vigneshwaran Sankar

Indian Institute of Technology Kanpur

Nichith Chandrasekaran

Indian Institute of Science Bangalore

Sulthan Ariff Rahman Mohamed Rafic

Kumaraguru College of Technology, India

Ajith Sukumaran

Kumaraguru College of Technology, India

Pradeep Kumar Radhakrishnan

GITAM University

Shiv Kumar Choudhary

All India Institute of Medical Sciences

\section{Research Article}

Keywords: 3D Boundary layer blockage, Acute-heart-failure, DDT, Diabatic Nanoscale Flows, Sanal Flow Choking, Streamtube Flow Choking, Hemorrhagic Stroke, Nanoscale system, Zero slip length

Posted Date: March 26th, 2021

DOl: https://doi.org/10.21203/rs.3.rs-356645/v1

License: (c) (1) This work is licensed under a Creative Commons Attribution 4.0 International License. Read Full License

Version of Record: A version of this preprint was published at Scientific Reports on July 29th, 2021. See the published version at https://doi.org/10.1038/s41598-021-94450-8. 


\title{
Sanal Flow Choking in Nanoscale Fluid Flow Systems at the
}

\section{Zero Slip Length: Universal Benchmark Data for 3D in Silico,}

\author{
in Vitro and in Vivo Experiments
}

\section{Running Title: An Exact Prediction of the 3D Blockage Factor in}

\section{Diabatic Nanoscale Fluid Flow Systems}

V.R.Sanal Kumar, ${ }^{1-3, *}$ Vigneshwaran Sankar, ${ }^{2-4}$ Nichith Chandrasekaran, ${ }^{2,3}$ Sulthan Ariff Rahman Mohamed Rafic, ${ }^{3}$ Ajith Sukumaran, ${ }^{3}$ Pradeep Kumar Radhakrishnan, ${ }^{5}$ Shiv Kumar Choudhary ${ }^{6}$

${ }^{1}$ Indian Space Research Organisation, VSSC, Trivandrum 695 022, Kerala, India

${ }^{2}$ Indian Institute of Science, Bangalore, Karnataka, 560012, India

${ }^{3}$ Kumaraguru College of Technology, Coimbatore - 641 049, Tamil Nadu, India

${ }^{4}$ Indian Institute of Technology, Kanpur 208016, Uttar Pradesh, India

${ }^{5}$ GITAM University, Visakhapatnam-530045, Andhra Pradesh, India

${ }^{6}$ All India Institute of Medical Sciences, New Delhi - 110608, India

*Corresponding Author: Email: vr_sanalkumar@yahoo.co.in, Phone: +91-8754200501

KEY WORDS: 3D Boundary layer blockage, Acute-heart-failure, DDT, Diabatic Nanoscale Flows, Sanal

Flow Choking, Streamtube Flow Choking, Hemorrhagic Stroke, Nanoscale system, Zero slip length,

\section{ABSTRACT:}

Although the interdisciplinary science of nanotechnology has been advanced significantly over the last few decades there were no closed-form analytical models to predict the three-dimensional (3D) boundary-layer-blockage (BLB) factor, of diabatic flows (flows involves the transfer of heat) passing through a nanoscale tube. As the pressure of the diabatic nanofluid and/or non-continuumflows rises, average-mean-free-path diminishes and thus, the Knudsen number lowers heading to a zero-slip wall-boundary condition with the compressible viscous flow regime in the nano scale tubes 
leading to Sanal flow choking [PMCID: PMC7267099; Physics of Fluids, DOI: 10.1063/5.0040440] creating a physical situation of the sonic-fluid-throat effect in the tube at a critical-total-to-static pressure ratio (CPR). Herein, we presented a closed-form-analytical-model, which is capable to predict exactly the 3D-BLB factor at the Sanal flow choking-condition of nanoscale diabatic fluid flow systems at the zero-slip-length. The innovation of Sanal flow choking model in the nanoscale fluid flow system is established herein through the entropy relation, as it satisfies all the conservation laws of nature. The exact value of the 3D-BLB factor in the sonic-fluidthroat region presented herein for each gas is a universal benchmark data for performing highfidelity in silico, in vitro and in vivo experiments for the lucrative design optimization of nanoscale fluid flow systems in gravity and microgravity environments and also for drug discovery for prohibiting asymptomatic cardiovascular diseases in Earth and human spaceflight < doi.org/10.2514/6.2021-0357>. Note that the relatively high and low-blood-viscosity (creating high turbulence) leads to the Sanal flow choking causing asymptomatic cardiovascular diseases. Such diseases in the cardiovascular system can be negated by maintaining the systolic-to-diastolic blood pressure ratio lower than the CPR $<\mathbf{1 0 . 1 0 0 2 / g c h 2 . 2 0 2 0 0 0 0 7 6}>$. The CPR is regulated by the heat capacity ratio (HCR) of the fluid. Note that HCR is the key parameter, which could control simultaneously blood viscosity and turbulence. The physical insight of the boundary-layer-blockage persuaded nanoscale Sanal flow choking in diabatic flows presented in this article sheds light on finding solutions to numerous unresolved scientific problems in physical, chemical and biological systems carried forward over the centuries because the closed-form analytical model describing the phenomenon of Sanal flow choking is a unique scientific language of the real-world-fluid flows. More specifically, mathematical models presented herein are capable to forecast the limiting conditions of deflagration to detonation transition (DDT) in nanoscale systems and beyond with confidence. Additionally, the Sanal flow choking condition will forecast the asymptomatichemorrhage and acute-heart-failure https://www.ahajournals.org/doi/10.1161/str.52.suppl_1.P804. Briefly, the undesirable Sanal flow choking causing detonation and hemorrhagic stroke can be negated by increasing the HCR of the fluid. 
The theoretical finding of the Sanal-flow-choking and streamtube-flow-choking ${ }^{\mathbf{1}, 2}$ (Figure 1a) is a methodological advancement in the modeling of the continuum and non-continuum real-world composite fluid flows at the creeping-inflow (low subsonic flow) conditions. The closed-form analytical model conceiving all the conservation laws of nature at the Sanal flow choking condition for diabatic flow is certainly the unique scientific language of the Universe, which we are presenting herein for solving various unresolved problems carried forward over the centuries. Cognizing physics of multi-phase and multi-species fluid-flows and controlling the composite flow at the nanoscale is vital for inventing, manufacturing, and lucrative performance improvements of nano-electro-mechanical systems (NEMS) for high precision applications. ${ }^{3-10}$ The design of such systems are currently a subject of great interest in aerospace, chemical, material, biomedical and allied industries. This is particularly true for the design optimization of certain aerospace systems in the international space station (ISS) and the nanoscale-thrusters ${ }^{11}$ operating at both gravity and microgravity environments where the flow field exhibit both the continuum and non-continuum fluid properties. In such physical situations multiscale and hybrid modeling approaches are encouraged. ${ }^{\mathbf{1 2}}$

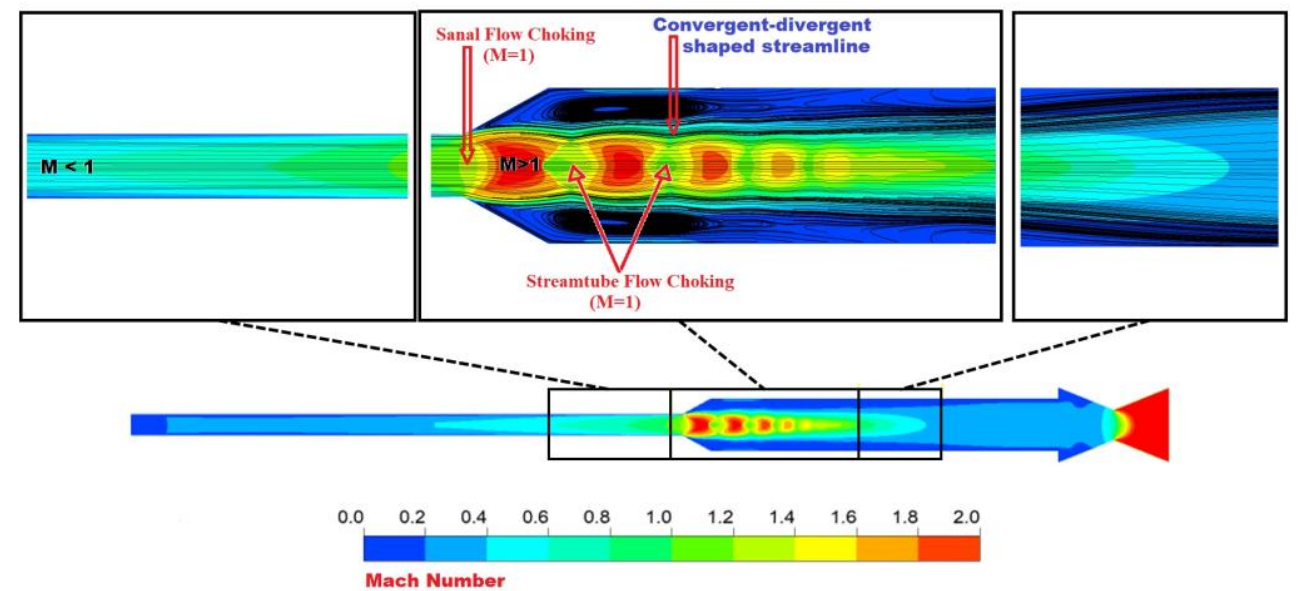

Figure 1a. The enlarged view of the Sanal flow choking and the streamtube flow choking phenomena in an idealized physical model of an internal fluid flow system <Movie: https://youtu.be/bv3ZDcPKMSI>. 


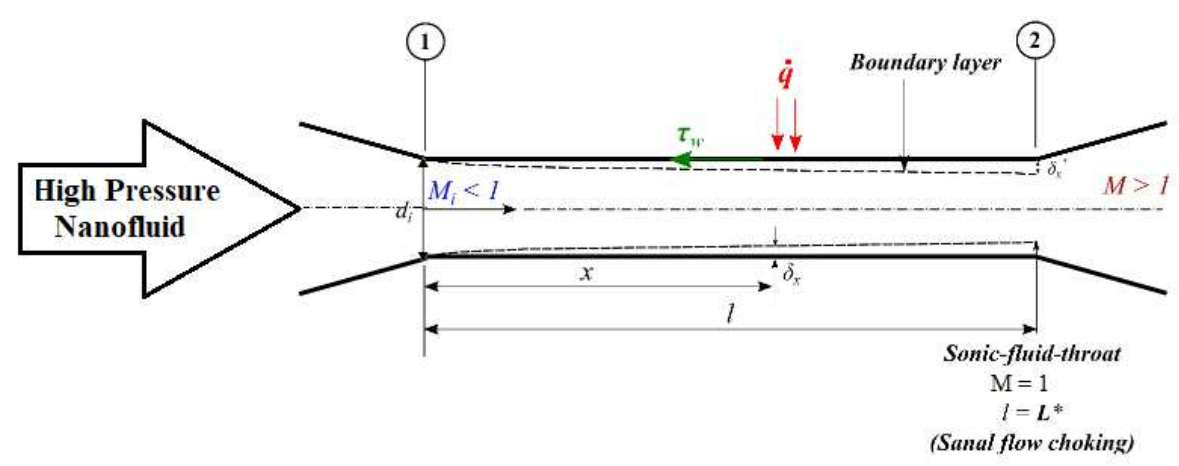

Figure 1b. Demonstrating the Sanal flow choking condition in an idealized physical model of an internal nanoscale fluid flow system.

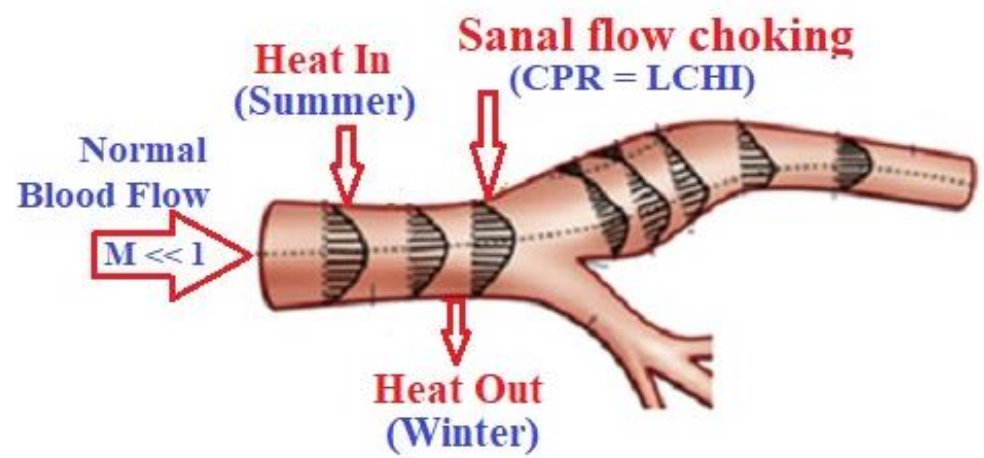

Figure 1c. Seasonal variations and the Sanal flow choking in an artery with bifurcation and without any plaque

Although mathematical modeling and the high-fidelity in silico simulation of physics of noncontinuum/nanofluid flow have been progressed substantially over the last few decades there are numerous unanswered research questions in real-world fluid flows ${ }^{\mathbf{1 - 1 0}}$ for a plausible judgment on the biological and space systems design. Such problems of paramount interest are chiefly for performing in silico and in vitro experiments for the design optimization of nano scale aerospace propulsion devices and in vivo animal model experiments for drug discovery. Therefore, it is inevitable for capturing flow physics of high-pressure composite creeping fluid flow passing through a convergent-divergent (CD) duct, facilitated with a nanoscale throat with microscale length (Figure 1b) featuring both the continuum and non-continuum fluid flow properties. Figure 1c is demonstrating the possibilities of the occurrence of the Sanal flow choking phenomenon at a CPR due to seasonal variations in a nano scale artery with bifurcation and without any plaque. 


\section{Nature}

Nanofluid flow is a blend of nano-sized particles in a traditional operating fluid, ${ }^{\mathbf{1 0 - 1 2}}$ which obeys all the conservation laws of nature. The occurrence of slip in gas flows, due to the local thermodynamic non-equilibrium, was originally reported by Maxwell ${ }^{\mathbf{1 4 , 1 5}}$ and its scale varies on the extent of rarefaction of the gas. It describes in terms of the Knudsen number $(K n)$, which gives an explicit clue on the type of flow, viz., the continuum or non-continuum. Note that numerous modeling efforts have been reported in the open literature for nanoscale flow simulation without authentic code verification using any benchmark data and/or any closed-form analytical solution. ${ }^{\mathbf{1 6 - 3 5}}$ The fact is that generating benchmark data from the nanoscale system is a challenging task or quite impractical by using a conventional in vitro methods and/or in vivo animal models. And it is anticipated that the classical assumptions on the hydrodynamic model will ride into

hitches as the composite flow system reaches nanometer (nm) size. ${ }^{19}$ Obviously, due to the lack of universal benchmark data for an authentic verification of the in silico results, the conclusions drawn using sophisticated models, by various investigators across the globe, viz., direct simulation Monte Carlo (DSMC), molecular dynamics (MD), Burnett equation and the hydrodynamic models, will not be endorsed by the high precision industries for the highly expensive nanoscale systems designs for practical applications. It is patently true for the decision making on health care management too without providing an exact solution for the data verification. Note that nanoscale drug delivery devices can be tailored for site-specific therapeutic activity. ${ }^{\mathbf{3 6 - 3 8}}$

Cooper et al. ${ }^{19}$ reported that in vitro data well matched with the predicted results using the hydrodynamic Navier Stokes method with the first-order slip condition for the range of average pore diameters from 169-220 nm. Singh and Myong ${ }^{39}$ reported that neither continuum models nor free-molecular models could be invoked for fluid flow cases when the Knudsen number falls in the intermediate range between the continuum $(K n \leq 0.01)$ and free-molecular flow regimes 
$(K n \geq 10)$. When the Knudsen number becomes large $(K n>0.01)$, the conventional assumptions of no-slip boundary condition, thermodynamic equilibrium, and linear stress-strain relationship fail. Admittedly, when the pressure of the nano fluid rises, the average-mean-free-path diminishes and thus, the Knudsen number lowers heading to a zero-slip wall-boundary condition with the compressible viscous flow regime creating streamline pattern in the nanoscale fluid flow system. Therefore, the Sanal flow choking and supersonic flow development leading to the shock-wave generation due to the fluid-throat effect at the zero-slip-length is a valid physical situation in the real-world fluid flows where CD shaped nanoscale streamtubes persists (Figure 1a). Herein, we provide a proof of the concept of fluid-throat persuaded flow choking in the nanoscale diabatic fluid flow system. For establishing this concept authoritatively, we are presenting an infallible closed-form analytical model for predicting the three-dimensional (3D) boundary layer displacement thickness (defined herein as the 3D-BLB factor) of a nano scale fluid flow system (Figure 1b) at the sonic-fluid-throat location where the slip length is zero, which will be a useful tool for the in silico, in vitro and in vivo experiments in both the continuum and non-continuum flows with due consideration of heat transfer effects (real-world fluid flow effect).

D.M.Holland et al. $^{\mathbf{4 0}}$ reported (2015) that the time dependent mass flow rate predicted using their enhanced computational fluid dynamics (CFD) simulation matches well with full molecular dynamics (MD) simulation and highlighted that the traditional CFD results of such cases are incompetent. Of late (2020), Chengxi Zhao ${ }^{\mathbf{4 1}}$ reported that the soundness of the traditional theories at the microscale and nanoscale has been taken into question. Authors reported that the thermal fluctuations are spontaneously occurring within molecular dynamics (MD) simulations. The study conclusions of the previous researchers ${ }^{32-47}$ lead to say that in real-world scientific experiments of complex nano-microscale systems the robustness of in silico model needs to be tested by featuring 
the actual fluid characteristics in a non-trivial geometry at the nanoscale. Singh and Myong ${ }^{\mathbf{3 9}}$ reported that for improved modeling efforts, the joint effect of material properties, the scale and shape of the flowing medium on fluid flow must be taken into account, which is lacking now and hence we are addressing it herein through the closed-form analytical models satisfying the Sanal flow choking condition in diabatic nano scale fluid flow systems. Sanal flow choking ${ }^{\mathbf{1 2}}$ is a compressible viscous flow effect, which occurs in any duct with uniform port geometry, due to the boundary layer blockage persuaded internal flow choking at a critical-total-to-static pressure ratio (CPR), as all real-world-fluids experience the Sanal flow choking phenomenon. ${ }^{\mathbf{1}}$ The CPR for flow choking (Equation 1) ${ }^{\mathbf{1}}$ of composite fluids would vary based on the lowest heat capacity ratio (HCR) of the evolved species at the constriction region (fluid-throat) of the streamtube or nano scale tube (Figure 1a-c). Note that the molecular dynamic condition in the composite fluid flow system could alter streamline-pattern at different time and location. Therefore, pinpointing the exact location of streamtube flow choking (Figure 1a) at the Sanal flow choking condition is a challenging in vitro and in silico topic of great interest to the nano-microscale system designers.

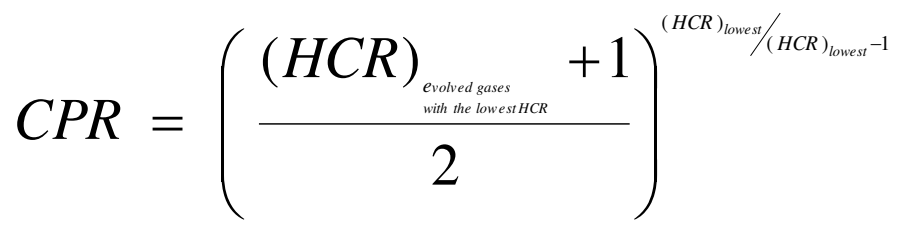

$$
\begin{aligned}
& 3 D-\left.B L B\right|_{\substack{\text { बrhe epstream port } \\
\text { of the nano scalessytem }}}=\frac{2 \delta_{x}}{d_{\text {inlet }}}=1-\left[\frac{M_{\text {inflow }}}{M_{\text {axial }}}\right]^{1 / 2}\left[\frac{1+\frac{\gamma-1}{2} M_{\text {axial }}^{2}}{1+\frac{\gamma-1}{2} M_{\text {inflow }}^{2}}\right]^{\frac{\gamma+1}{4(\gamma-1)}}
\end{aligned}
$$

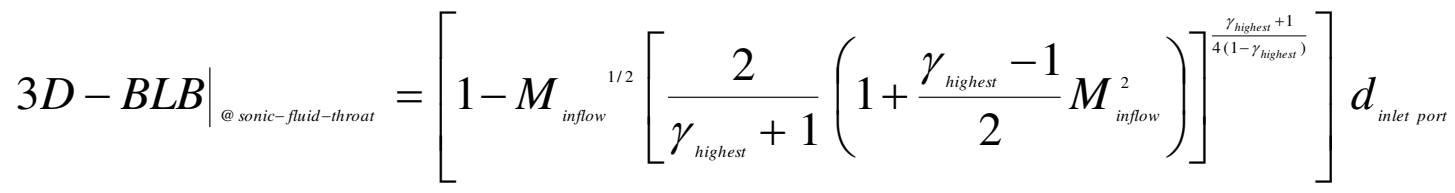




$$
\begin{aligned}
& \frac{1+\gamma_{\text {lowest }}}{1+\gamma_{\text {lowest }} M_{\text {inflow }}^{2}}=\left(\frac{\gamma_{\text {lowest }}+1}{2}\right)^{\frac{\gamma_{\text {lowest }}}{\gamma_{\text {lowes }}-1}}
\end{aligned}
$$

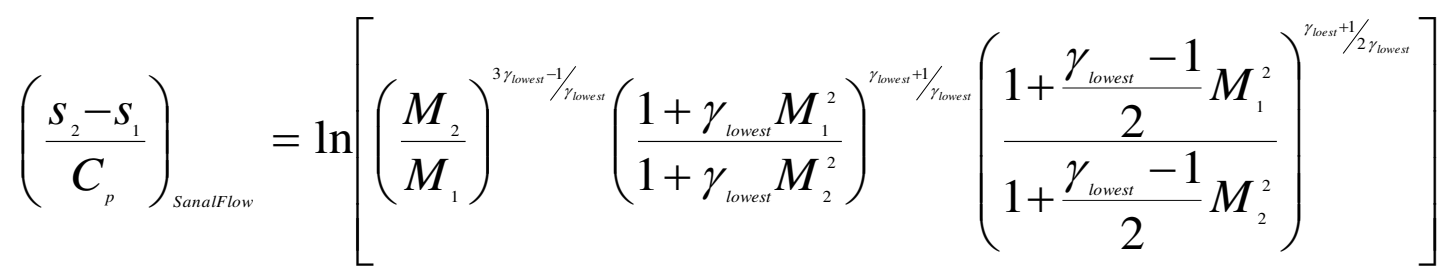

The 3D-BLB factor derived for an internal flow system with the cylindrical upstream-duct for adiabatic fluid flow systems ${ }^{2}, \mathbf{4 8}$ is translated herein for diabatic nanoscale flow systems with a desirable inflow condition and presented herein as Equation 2a-b. Equation 3 is derived using Equation 1 and the thermal choking (Rayleigh flow effect ${ }^{48}$ ) condition. It gives the desirable inflow condition in terms of Mach number for achieving Sanal flow choking in a nano scale diabatic fluid flow system, which is regulated by the material property viz., HCR. The solution curve of Equation 3 is presented as Figure 2a. Note that the chances of Sanal flow choking increases when the specific heat ratio (HCR) of gases decreases due to the decreases in CPR of the nanoscale flow system as dictated by Equation 1. Equation 2a gives the exact solution of the 3DBLB factor along the axial direction of the nano scale system, provided the local axial Mach number $\left(\mathrm{M}_{\text {axial }}\right)$ is known. Note that $\mathrm{M}_{\text {axial }}$ alters due to the flow turbulence and as on today there is no closed-form analytical solution for predicting $M_{\text {axial }}$ at the unchoked fluid flow condition, which is a challenging research topic. Note that Equation $\mathbf{2 b}$ provides an exact solution of the 3DBLB factor at the sonic-fluid-throat $\left(\mathrm{M}_{\text {axial }}=1\right)$ with molecular precision at the condition prescribed by the Sanal-flow-choking for diabatic fluid flows, which is an authorized benchmark data for the verification of the results generated from in vitro, in silico and in vivo experiments of real-world nanoscale fluid flow problems. Note that in the multispecies-choked-nanoscale internal 
fluid flow system, the highest 3D-BLB factor created at the sonic-fluid-throat (Equation 2b) will be contributed by the species with the highest HCR. The 3D-BLB factor is a very useful benchmark data for nanoscale in vitro experiments and in silico model verification, validation and calibration with credibility, which was an unresolved problem over centuries. The corresponding nondimensional blockage factor for the two-dimensional ${ }^{2}$ case is also given in Table-1 (Vigneshwaran's Table of Exact Solutions) as benchmark data for comparison at the Sanal flow choking condition for real-world flows. The solution curve of Equation 2a for Methane gas is given in Figure 2b and the solution curve of Equation $\mathbf{2 b}$ for Hydrogen gas is depicted in Figure 2c. The entropy relationship developed for the Sanal flow model altogether conceived the Rayleigh flow model and Fanno flow model effects and presented herein as Equation $\mathbf{4}$ and its solution is given in Figure 2d with air as the operating fluid. The entropy-Mach number comparisons of Fanno flow, Rayleigh flow and Sanal flow models are shown in Figure 2e. The innovation of the Sanal-flow-choking model is established herein through the entropy relation (Equation 4), as it satisfies all the conservation laws of nature.

Table 1. Benchmark Data: Vigneshwaran's Table of Exact Solutions of Blockage Factor

\begin{tabular}{|c|c|c|c|c|c|c|}
\hline \multirow{3}{*}{$\begin{array}{l}\text { Sl } \\
\text { No. }\end{array}$} & \multirow{3}{*}{ Type of Gas } & \multirow{3}{*}{$\gamma$} & \multicolumn{4}{|c|}{ Sanal Flow Choking Condition for Diabatic Nano Flows } \\
\hline & & & & $\left(\frac{2 \delta_{x}^{*}}{d_{i}}\right)$ & $\left(\frac{2 \delta_{x}^{*}}{d_{i}}\right)$ & $\begin{array}{l}\mathrm{LCDI} \\
(C P R)\end{array}$ \\
\hline & & & $\mathrm{M}_{\mathrm{i}}$ & $2 \mathrm{D}$ & $3 \mathrm{D}$ & \\
\hline 1 & Air & 1.400 & 0.4374 & 0.3247 & 0.1782 & 1.8929 \\
\hline 2 & Argon & 1.667 & 0.4236 & 0.3296 & 0.1812 & 2.0530 \\
\hline 3 & $\mathrm{CO}_{2}$ & 1.289 & 0.4437 & 0.3224 & 0.1768 & 1.8257 \\
\hline 4 & Helium & 1.667 & 0.4236 & 0.3296 & 0.1812 & 2.0530 \\
\hline 5 & Hydrogen & 1.405 & 0.4372 & 0.3248 & 0.1783 & 1.8959 \\
\hline 6 & Methane & 1.299 & 0.4431 & 0.3226 & 0.1770 & 1.8318 \\
\hline 7 & Nitrogen & 1.400 & 0.4374 & 0.3247 & 0.1782 & 1.8929 \\
\hline 8 & Octane & 1.044 & 0.4587 & 0.3169 & 0.1735 & 1.6759 \\
\hline 9 & Oxygen & 1.395 & 0.4377 & 0.3246 & 0.1782 & 1.8899 \\
\hline 10 & Steam & 1.327 & 0.4415 & 0.3232 & 0.1773 & 1.8488 \\
\hline
\end{tabular}




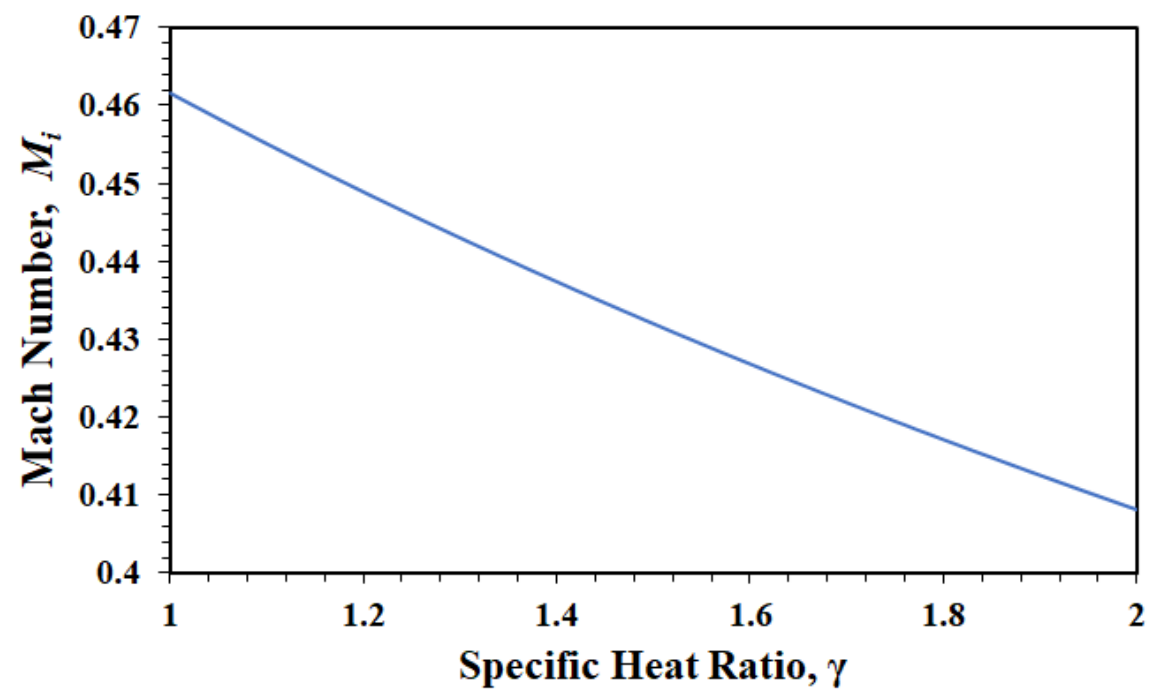

Figure 2a. The inlet Mach number prediction of different gases with different HCR $(\gamma)$ for achieving Sanal flow choking condition for diabatic nano scale flows.

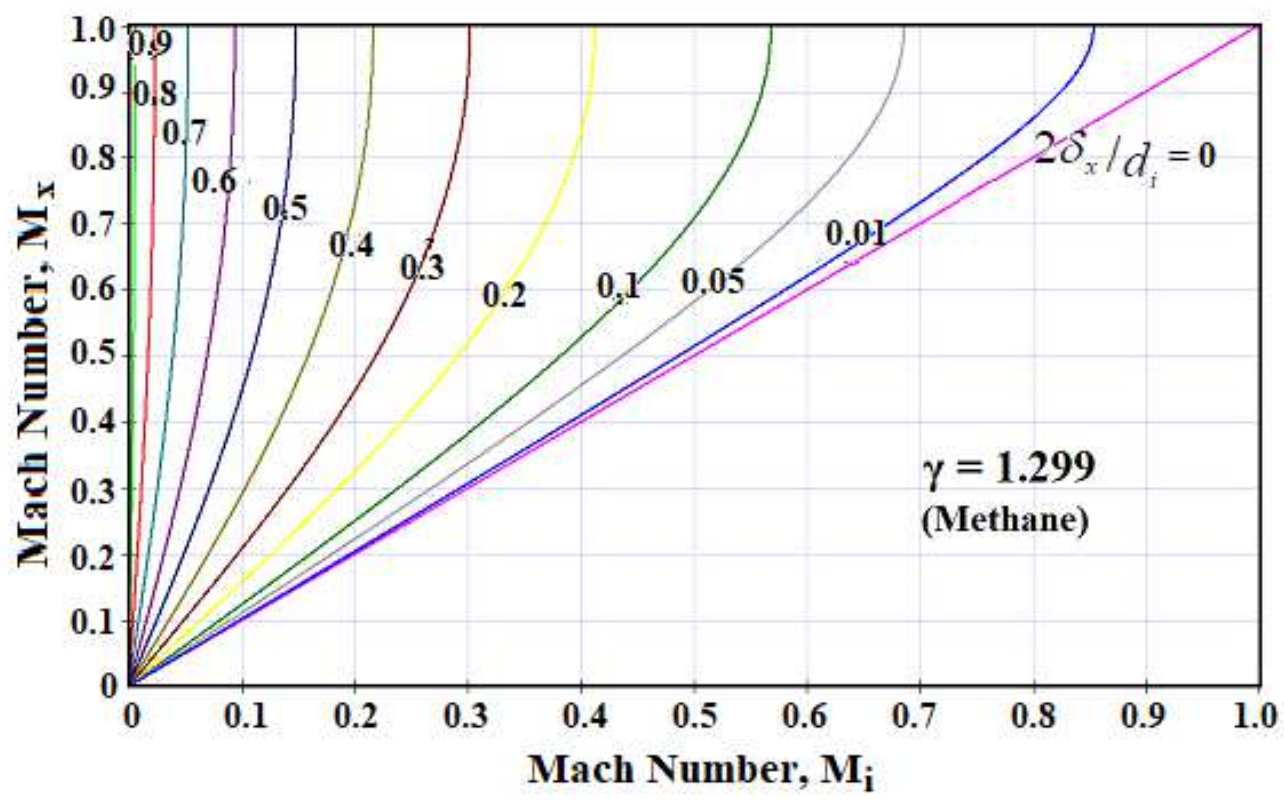

Figure 2b. The solution curve of Equation 2a is showing the 3D blockage factor with Methane as the working fluid. 


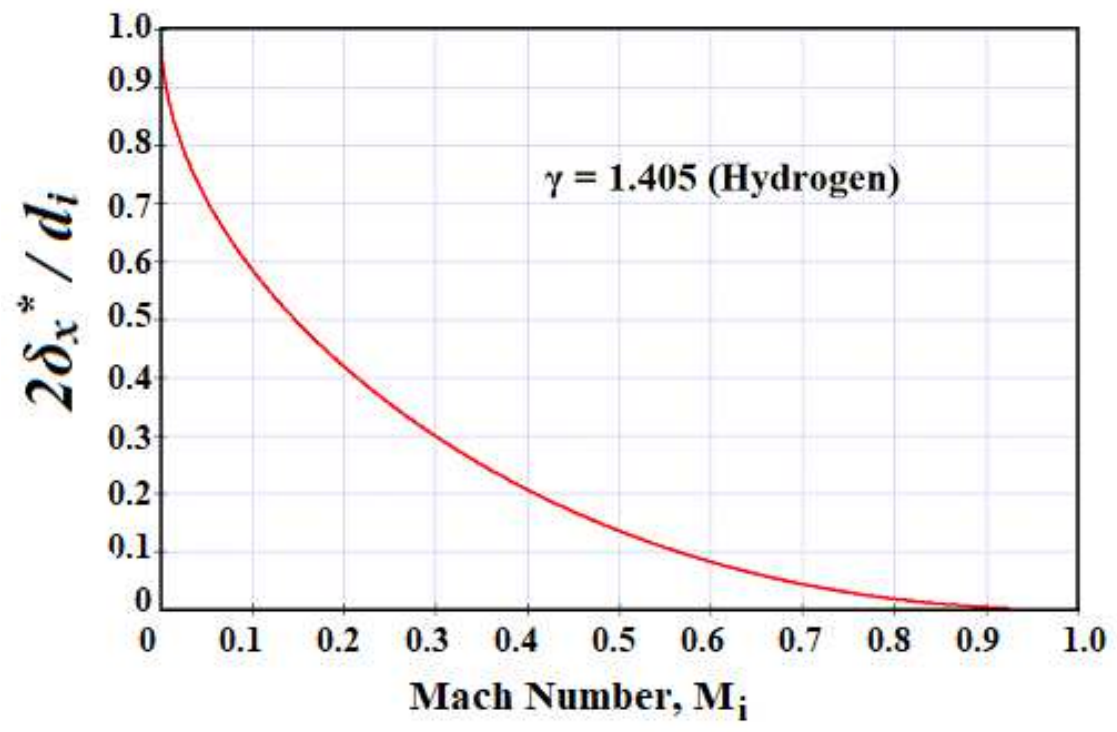

Figure 2c. The solution curve of Equation $2 b$ is showing the 3D blockage factor in the sonic-fluid-throat of a nano scale fluid flow system with hydrogen as the working fluid.

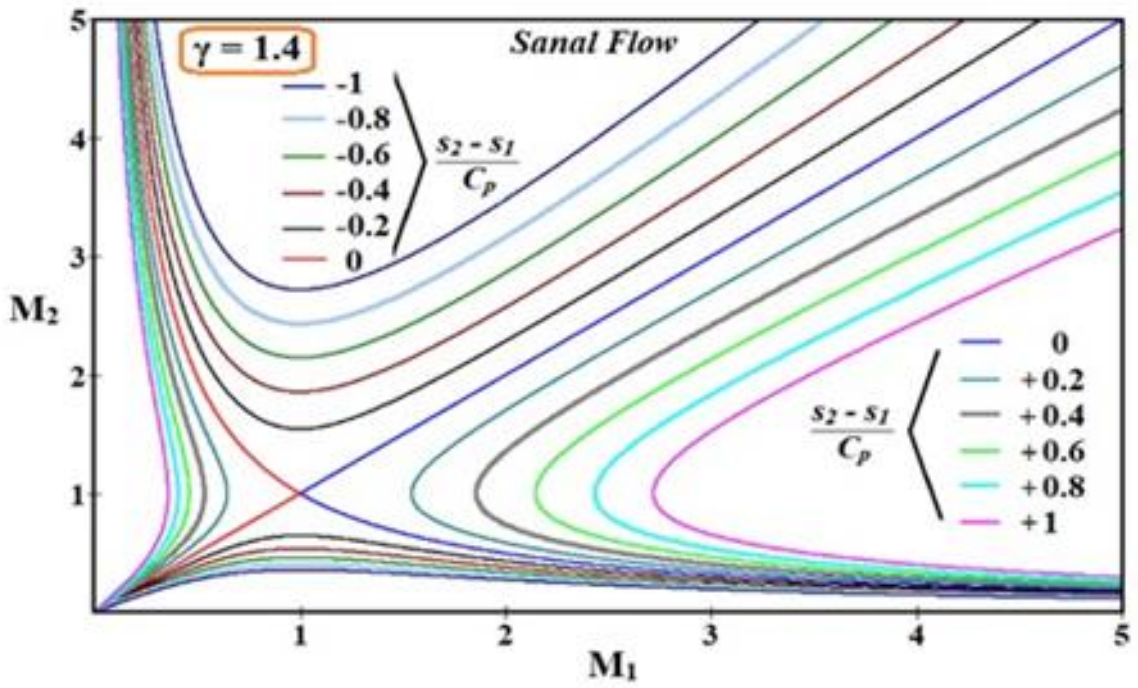

Figure 2d. The demonstration of the Sanal flow choking in diabatic nano scale fluid flows. (Solution curves of Equation 4). 


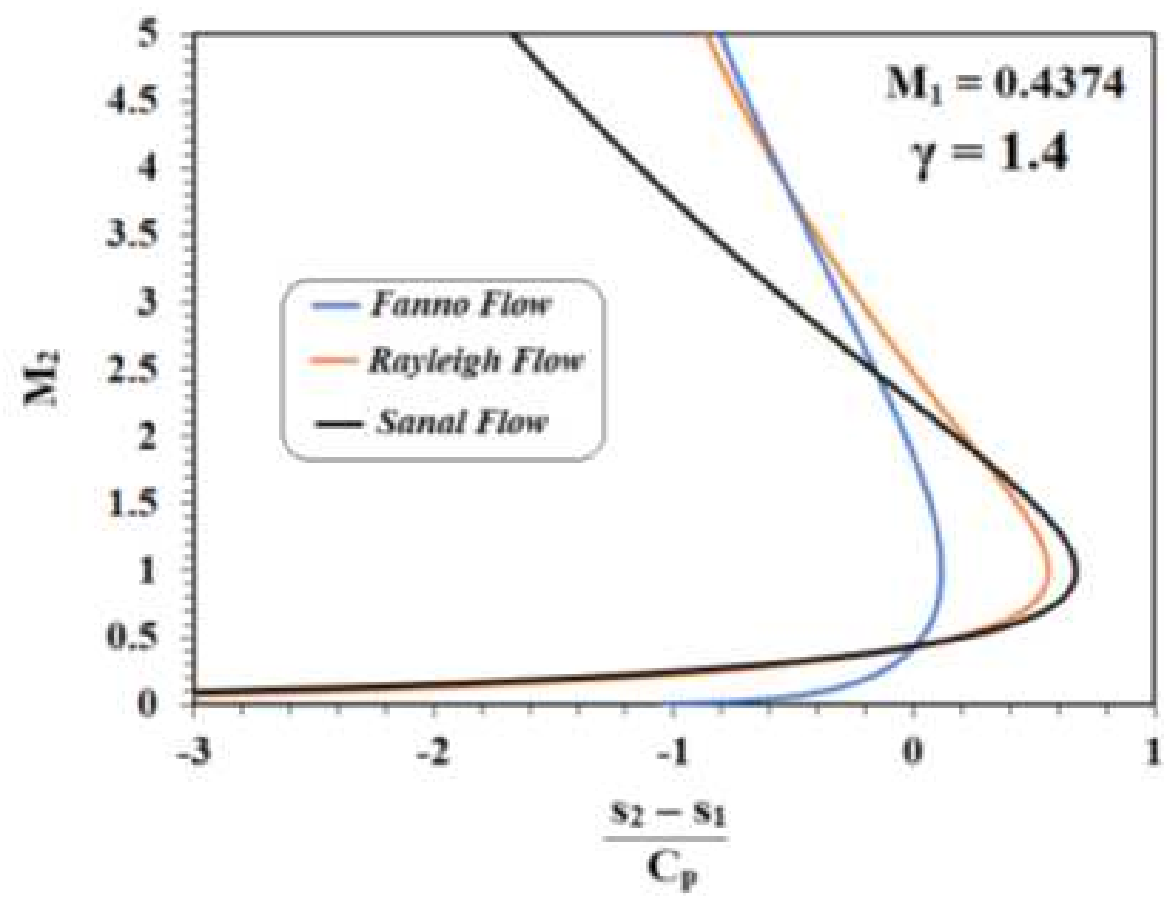

Figure 2e. Mach Number-Entropy chart of Fanno, Rayleigh and Sanal flow models at the choked flow condition.

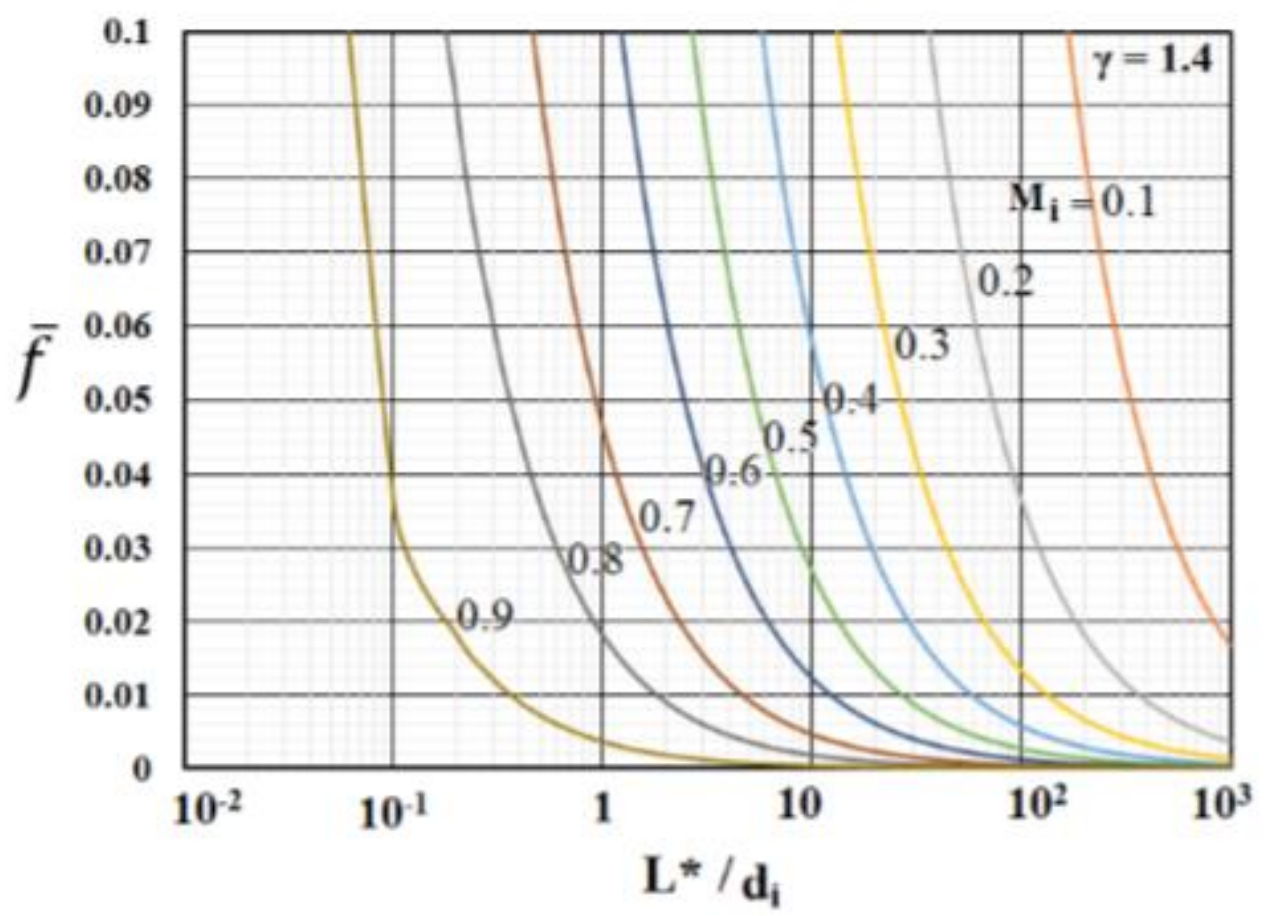

Figure 2f. Analytical predictions of the average friction coefficient at the Sanal flow choking condition of different nanotubes at different inlet conditions. 
It is apparent from Figure $2 \mathbf{d}$ that the change in entropy is obtained as zero at $M_{1}=M_{2}=1$, which is validating the capability of the model for meeting the Sanal flow choking condition for the nanoscale fluid flow systems for benchmarking the data reported in Table-1. It could be taken as the authenticated data for elucidating high fidelity wall-bounded nanoscale fluid flow problems in various industrial applications. The CPR value is an indication of the lower critical detonation index (LCDI) of the internal flow systems having accumulated with such types of working fluids. The LCDI presented in Table-1 is a powerful indicator of knowing the detonation index of nanoscale chemical energy systems with sudden expansion or divergent port for prohibiting the catastrophic failures due to the Sanal flow choking and/or streamtube flow choking (Figure 1a).

It is important to note that, at the sonic-fluid-throat of any wall-bounded real-world flows, all the three flow choking conditions, viz., Sanal flow choking ${ }^{\mathbf{1}, \mathbf{2}}$, Rayleigh flow choking ${ }^{\mathbf{4 8}}$ and Fanno flow choking $\mathbf{4 8}^{\mathbf{8}}$ converge due to the prudent inflow condition (Equation 3 ) set herein for generating benchmark data for nano scale fluid flow systems. It is pertinent to note that the magnitude of the entropy of these three flow choking models are different at the sonic condition. The novelty of the closed-form analytical model presented herein stem from the veracity that at the Sanal flow choking condition for diabatic nanoflows, all conservation laws of nature are satisfied in the unique sonic-fluid-throat location. In this letter analytical models are presented for establishing the causes and effects of the Sanal flow choking in an internal nanoscale fluid flow system with sudden expansion or divergent region.

While performing the in silico model verification and calibration, the average friction coefficient must be chosen in accordance with the Fanno flow choking condition., ${ }^{\mathbf{2} 48}$ Admittedly, at the sonic-fluid-throat of the nanoscale fluid flow system (Figure 1b), the thermal choking and the wall-friction persuaded flow choking converge and satisfy all the conservation laws of nature. 
In the in silico study the average friction coefficient $(\bar{f}$ )may be estimated from Equation 5 based on the lowest HCR ( $\gamma$ lowest) of the evolving gases for satisfying the condition set for the Sanal flow choking for real-world multiphase, multi-species nanoscale fluid-flow systems. ${ }^{2}$

$$
\bar{f}=\frac{d_{i}}{4 L^{*}}\left[\frac{1-M_{i}^{2}}{\gamma_{\text {lowest }} M_{i}^{2}}+\frac{\gamma_{\text {lowest }}+1}{2 \gamma_{\text {lowest }}} \ln \left[\frac{\left(\gamma_{\text {lowest }}+1\right) M_{i}^{2}}{2+\left(\gamma_{\text {lowest }}-1\right) M_{i}^{2}}\right]\right]
$$

where $\bar{f}$ is an average friction coefficient ${ }^{2,48}$ termed as Equation 6,

$$
\bar{f}=\frac{1}{L^{*}} \int_{0}^{L^{*}} f d x
$$

The solution curve of Equation 5 is given in Figure $2 \mathbf{f}$ in the semi-log plot.

Note that, though the 3D-BLB factor is relatively less for cases with the low HCR, the dominant species with the lowest HCR predisposes for an early Sanal flow choking due to the low CPR at the sudden expansion or transition region of any internal nano scale fluid flow system (Figure 1a). Note that Equations 1-6 are useful mathematical models for the high-performance aerospace chemical systems architects for predicting the limiting condition of deflagration to detonation transition (DDT) in nanoscale thrusters with confidence. Further discussion pertaining to the nanoscale chemical system design is beyond the scope of this letter. This letter is set for predicting the universal benchmark data at the Sanal flow choking condition for in silico, in vitro and in vivo experiments in nanoscale fluid flow systems for various applications. 
Vigneshwaran's Table (Table-1) gives the exact values of the non-dimensional 3D-BLB factor at the Sanal flow choking condition of ten different working gases and the corresponding CPR and inlet Mach number. It is pertinent to state that, as seen in Table-1, the three-dimensional blockage factor is always lower than the two-dimensional blockage factor of any wall-bounded nanoscale fluid flow system at the Sanal flow choking condition. The average friction coefficient given in Table-2 (the solution of Equation 5) for different gases are the authenticated benchmark data generated from the closed-form analytical models for conducting in silico experiments with credibility.

Table 2 : Vigneshwaran's Table of Exact Solution

\begin{tabular}{|c|c|c|c|c|c|c|}
\hline \multirow{2}{*}{$\begin{array}{c}\text { Inlet Mach } \\
\text { Number } \\
\left(\mathbf{M}_{\mathbf{i}}\right)\end{array}$} & \multicolumn{5}{|c|}{ Average Friction Coefficient $(\bar{f})$} & $\mathbf{L}^{*} / \mathbf{d}_{\mathbf{i}}=\mathbf{2 7}$ \\
\cline { 2 - 7 } & $\mathbf{L}^{*} / \mathbf{d}_{\mathbf{i}}=\mathbf{2 8}$ & $\mathbf{L}^{*} / \mathbf{d}_{\mathbf{i}}=\mathbf{3 5}$ & $\mathbf{L}^{*} / \mathbf{d}_{\mathbf{i}}=\mathbf{8 5}$ & $\mathbf{L}^{*} / \mathbf{d}_{\mathbf{i}}=\mathbf{1 5 0}$ & $\mathbf{L}^{*} / \mathbf{d}_{\mathbf{i}}=\mathbf{3 0 0}$ \\
\hline 0.02 & 16.467129 & 15.879017 & 12.703213 & 5.230735 & 2.964083 & 1.482042 \\
\hline 0.04 & 4.077335 & 3.931716 & 3.145373 & 1.295154 & 0.733920 & 0.366960 \\
\hline 0.06 & 1.787325 & 1.723492 & 1.378793 & 0.567738 & 0.321718 & 0.160859 \\
\hline 0.08 & 0.988132 & 0.952841 & 0.762273 & 0.313877 & 0.177864 & 0.088932 \\
\hline 0.1 & 0.619644 & 0.597514 & 0.478011 & 0.196828 & 0.111536 & 0.055768 \\
\hline 0.12 & 0.420444 & 0.405428 & 0.324343 & 0.133553 & 0.075680 & 0.037840 \\
\hline 0.14 & 0.301031 & 0.290280 & 0.232224 & 0.095621 & 0.054186 & 0.027093 \\
\hline 0.16 & 0.224054 & 0.216052 & 0.172842 & 0.071170 & 0.040330 & 0.020165 \\
\hline 0.18 & 0.171691 & 0.165559 & 0.132448 & 0.054537 & 0.030904 & 0.015452 \\
\hline 0.2 & 0.134567 & 0.129761 & 0.103809 & 0.042745 & 0.024222 & 0.012111 \\
\hline 0.22 & 0.107371 & 0.103536 & 0.082829 & 0.034106 & 0.019327 & 0.009663 \\
\hline 0.24 & 0.086912 & 0.083808 & 0.067046 & 0.027607 & 0.015644 & 0.007822 \\
\hline 0.26 & 0.071181 & 0.068639 & 0.054911 & 0.022610 & 0.012813 & 0.006406 \\
\hline 0.28 & 0.058863 & 0.056761 & 0.045409 & 0.018698 & 0.010595 & 0.005298 \\
\hline 0.3 & 0.049067 & 0.047315 & 0.037852 & 0.015586 & 0.008832 & 0.004416 \\
\hline
\end{tabular}


Oxygen $-\gamma=1.395$

\begin{tabular}{|c|c|c|c|c|c|c|}
\hline \multirow{2}{*}{$\begin{array}{c}\text { Inlet Mach } \\
\text { Number } \\
\left(M_{i}\right)\end{array}$} & \multicolumn{6}{|c|}{ Average Friction Coefficient $(\bar{f})$} \\
\hline & $L^{*} / \mathbf{d}_{\mathbf{i}}=\mathbf{2 7}$ & $\mathbf{L}^{*} / \mathbf{d}_{\mathbf{i}}=\mathbf{2 8}$ & $L * / d_{i}=35$ & $L^{*} / d_{i}=85$ & $L^{*} / d_{i}=150$ & $L^{*} / d_{i}=300$ \\
\hline 0.02 & 16.526261 & 15.936037 & 12.748830 & 5.249518 & 2.974727 & 1.487363 \\
\hline 0.04 & 4.092037 & 3.945893 & 3.156714 & 1.299823 & 0.736567 & 0.368283 \\
\hline 0.06 & 1.793805 & 1.729740 & 1.383792 & 0.569797 & 0.322885 & 0.161442 \\
\hline 0.08 & 0.991738 & 0.956318 & 0.765055 & 0.315023 & 0.178513 & 0.089256 \\
\hline 0.10 & 0.621922 & 0.599711 & 0.479768 & 0.197552 & 0.111946 & 0.055973 \\
\hline 0.12 & 0.422002 & 0.406931 & 0.325545 & 0.134048 & 0.075960 & 0.037980 \\
\hline 0.14 & 0.302156 & 0.291364 & 0.233092 & 0.095979 & 0.054388 & 0.027194 \\
\hline 0.16 & 0.224899 & 0.216867 & 0.173493 & 0.071438 & 0.040482 & 0.020241 \\
\hline 0.18 & 0.172345 & 0.166190 & 0.132952 & 0.054745 & 0.031022 & 0.015511 \\
\hline 0.20 & 0.135084 & 0.130260 & 0.104208 & 0.042909 & 0.024315 & 0.012158 \\
\hline 0.22 & 0.107787 & 0.103938 & 0.083150 & 0.034238 & 0.019402 & 0.009701 \\
\hline 0.24 & 0.087252 & 0.084136 & 0.067309 & 0.027715 & 0.015705 & 0.007853 \\
\hline 0.26 & 0.071463 & 0.068911 & 0.055129 & 0.022700 & 0.012863 & 0.006432 \\
\hline 0.28 & 0.059099 & 0.056988 & 0.045590 & 0.018772 & 0.010638 & 0.005319 \\
\hline 0.30 & 0.049265 & 0.047506 & 0.038005 & 0.015649 & 0.008868 & 0.004434 \\
\hline
\end{tabular}

Carbon Dioxide $-\gamma=1.289$

\begin{tabular}{|c|c|c|c|c|c|c|}
\hline \multirow{2}{*}{$\begin{array}{c}\text { Inlet Mach } \\
\text { Number } \\
\left(M_{i}\right)\end{array}$} & \multicolumn{6}{|c|}{ Average Friction Coefficient $(\bar{f})$} \\
\hline & $L^{*} / \mathbf{d}_{\mathbf{i}}=\mathbf{2 7}$ & $\mathbf{L}^{*} / \mathbf{d}_{\mathrm{i}}=\mathbf{2 8}$ & $L^{*} / \mathbf{d}_{\mathrm{i}}=\mathbf{3 5}$ & $L * / d_{i}=85$ & $L^{*} / d_{i}=150$ & $L^{*} / \mathbf{d}_{\mathrm{i}}=\mathbf{3 0 0}$ \\
\hline 0.02 & 17.887824 & 17.248973 & 13.799179 & 5.682015 & 3.219808 & 1.609904 \\
\hline 0.04 & 4.430553 & 4.272319 & 3.417855 & 1.407352 & 0.797500 & 0.398750 \\
\hline 0.06 & 1.943020 & 1.873627 & 1.498901 & 0.617195 & 0.349744 & 0.174872 \\
\hline 0.08 & 1.074778 & 1.036393 & 0.829115 & 0.341400 & 0.193460 & 0.096730 \\
\hline 0.10 & 0.674383 & 0.650298 & 0.520238 & 0.214216 & 0.121389 & 0.060694 \\
\hline 0.12 & 0.457886 & 0.441533 & 0.353226 & 0.145446 & 0.082420 & 0.041210 \\
\hline 0.14 & 0.328069 & 0.316353 & 0.253082 & 0.104210 & 0.059053 & 0.029526 \\
\hline 0.16 & 0.244361 & 0.235634 & 0.188507 & 0.077621 & 0.043985 & 0.021992 \\
\hline 0.18 & 0.187399 & 0.180706 & 0.144565 & 0.059527 & 0.033732 & 0.016866 \\
\hline 0.20 & 0.146998 & 0.141748 & 0.113398 & 0.046693 & 0.026460 & 0.013230 \\
\hline 0.22 & 0.117388 & 0.113196 & 0.090556 & 0.037288 & 0.021130 & 0.010565 \\
\hline 0.24 & 0.095103 & 0.091706 & 0.073365 & 0.030209 & 0.017118 & 0.008559 \\
\hline 0.26 & 0.077959 & 0.075175 & 0.060140 & 0.024763 & 0.014033 & 0.007016 \\
\hline 0.28 & 0.064526 & 0.062222 & 0.049778 & 0.020497 & 0.011615 & 0.005807 \\
\hline 0.30 & 0.053838 & 0.051915 & 0.041532 & 0.017101 & 0.009691 & 0.004845 \\
\hline
\end{tabular}


Nitrogen $-\gamma=1.4$

\begin{tabular}{|c|c|c|c|c|c|c|}
\hline \multirow{2}{*}{$\begin{array}{c}\text { Inlet Mach } \\
\text { Number } \\
\left(\mathbf{M}_{\mathbf{i}}\right)\end{array}$} & \multicolumn{6}{|c|}{ Average Friction Coefficient $(\bar{f})$} \\
\cline { 2 - 7 } & $\mathbf{L}^{*} / \mathbf{d}_{\mathbf{i}}=\mathbf{2 7}$ & $\mathbf{L}^{*} / \mathbf{d}_{\mathbf{i}}=\mathbf{2 8}$ & $\mathbf{L}^{*} / \mathbf{d}_{\mathbf{i}}=\mathbf{3 5}$ & $\mathbf{L}^{*} / \mathbf{d}_{\mathbf{i}}=\mathbf{8 5}$ & $\mathbf{L}^{*} / \mathbf{d}_{\mathbf{i}}=\mathbf{1 5 0}$ & $\mathbf{L}^{*} / \mathbf{d}_{\mathbf{i}}=\mathbf{3 0 0}$ \\
\hline 0.02 & 16.467129 & 15.879017 & 12.703213 & 5.230735 & 2.964083 & 1.482042 \\
\hline 0.04 & 4.077335 & 3.931716 & 3.145373 & 1.295154 & 0.733920 & 0.366960 \\
\hline 0.06 & 1.787325 & 1.723492 & 1.378793 & 0.567738 & 0.321718 & 0.160859 \\
\hline 0.08 & 0.988132 & 0.952841 & 0.762273 & 0.313877 & 0.177864 & 0.088932 \\
\hline 0.1 & 0.619644 & 0.597514 & 0.478011 & 0.196828 & 0.111536 & 0.055768 \\
\hline 0.12 & 0.420444 & 0.405428 & 0.324343 & 0.133553 & 0.075680 & 0.037840 \\
\hline 0.14 & 0.301031 & 0.290280 & 0.232224 & 0.095621 & 0.054186 & 0.027093 \\
\hline 0.16 & 0.224054 & 0.216052 & 0.172842 & 0.071170 & 0.040330 & 0.020165 \\
\hline 0.18 & 0.171691 & 0.165559 & 0.132448 & 0.054537 & 0.030904 & 0.015452 \\
\hline 0.2 & 0.134567 & 0.129761 & 0.103809 & 0.042745 & 0.024222 & 0.012111 \\
\hline 0.22 & 0.107371 & 0.103536 & 0.082829 & 0.034106 & 0.019327 & 0.009663 \\
\hline 0.24 & 0.086912 & 0.083808 & 0.067046 & 0.027607 & 0.015644 & 0.007822 \\
\hline 0.26 & 0.071181 & 0.068639 & 0.054911 & 0.022610 & 0.012813 & 0.006406 \\
\hline 0.28 & 0.058863 & 0.056761 & 0.045409 & 0.018698 & 0.010595 & 0.005298 \\
\hline 0.3 & 0.049067 & 0.047315 & 0.037852 & 0.015586 & 0.008832 & 0.004416 \\
\hline & & & & & & \\
\hline
\end{tabular}

Helium $-\gamma=1.667$

\begin{tabular}{|c|c|c|c|c|c|c|}
\hline \multirow{2}{*}{$\begin{array}{c}\text { Inlet Mach } \\
\text { Number } \\
\left(\mathbf{M}_{\mathbf{i}}\right)\end{array}$} & \multicolumn{7}{|c|}{ Average Friction Coefficient $(\bar{f})$} \\
\cline { 2 - 7 } & $\mathbf{L}^{*} / \mathbf{d}_{\mathbf{i}}=\mathbf{2 7}$ & $\mathbf{L}^{*} / \mathbf{d}_{\mathbf{i}}=\mathbf{2 8}$ & $\mathbf{L}^{*} / \mathbf{d}_{\mathbf{i}}=\mathbf{3 5}$ & $\mathbf{L}^{*} / \mathbf{d}_{\mathbf{i}}=\mathbf{8 5}$ & $\mathbf{L}^{*} / \mathbf{d}_{\mathbf{i}}=\mathbf{1 5 0}$ & $\mathbf{L}^{*} / \mathbf{d}_{\mathbf{i}}=\mathbf{3 0 0}$ \\
\hline 0.02 & 13.824736 & 13.330996 & 10.664797 & 4.391387 & 2.488453 & 1.244226 \\
\hline 0.04 & 3.420418 & 3.298260 & 2.638608 & 1.086486 & 0.615675 & 0.307838 \\
\hline 0.06 & 1.497793 & 1.444300 & 1.155440 & 0.475769 & 0.269603 & 0.134801 \\
\hline 0.08 & 0.827028 & 0.797491 & 0.637993 & 0.262703 & 0.148865 & 0.074433 \\
\hline 0.10 & 0.517887 & 0.499391 & 0.399513 & 0.164505 & 0.093220 & 0.046610 \\
\hline 0.12 & 0.350858 & 0.338328 & 0.270662 & 0.111449 & 0.063154 & 0.031577 \\
\hline 0.14 & 0.250794 & 0.241837 & 0.193469 & 0.079664 & 0.045143 & 0.022571 \\
\hline 0.16 & 0.186338 & 0.179683 & 0.143746 & 0.059190 & 0.033541 & 0.016770 \\
\hline 0.18 & 0.142529 & 0.137438 & 0.109951 & 0.045274 & 0.025655 & 0.012828 \\
\hline 0.20 & 0.111499 & 0.107516 & 0.086013 & 0.035417 & 0.020070 & 0.010035 \\
\hline 0.22 & 0.088790 & 0.085619 & 0.068495 & 0.028204 & 0.015982 & 0.007991 \\
\hline 0.24 & 0.071727 & 0.069165 & 0.055332 & 0.022784 & 0.012911 & 0.006455 \\
\hline 0.26 & 0.058623 & 0.056530 & 0.045224 & 0.018622 & 0.010552 & 0.005276 \\
\hline 0.28 & 0.048376 & 0.046649 & 0.037319 & 0.015367 & 0.008708 & 0.004354 \\
\hline 0.30 & 0.040239 & 0.038802 & 0.031042 & 0.012782 & 0.007243 & 0.003622 \\
\hline
\end{tabular}


Note that the nanoscale biological fluid flow system must always maintain the flow Mach number less than one as dictated by Equation 7. Equation 7a-c is the corollary of the Equation 7 set for negating the undesirable Sanal flow choking and streamtube flow choking causing shock wave generation and pressure-overshoot. These equations (Equation 7a-c) are useful for deciding the thermophysical properties of nanomaterials and the corresponding base fluid for various nanoscale system design and developments, drug discovery and its applications.

$$
M_{\text {nanofuid }}<1
$$

$\frac{\text { Fluid flow rate }}{\text { Vessel cross sectional area }} \sqrt{\frac{(\text { Prandtl Number })(\text { Thermal Conductivity })}{(H C R)(\text { Density })\left(C_{p}\right)(\text { Dynamic Viscosity })(\text { Static Pressure })}}<1$

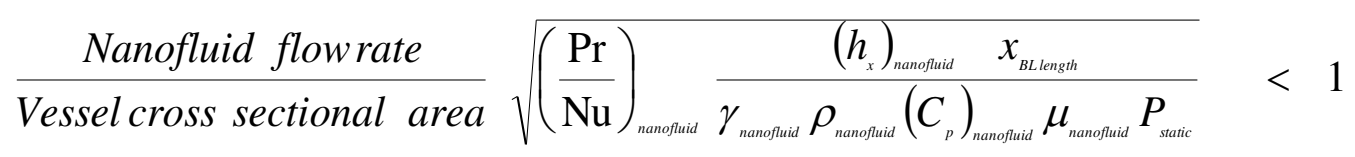

$$
\frac{R e_{\text {nanofluid }} v_{\text {nanofluid }}}{d_{H}}\left[\frac{\rho_{\text {nanofluid }}}{\gamma_{\text {nanofluid }}\left(P_{\text {static }}\right)_{\text {nanofluid }}}\right]^{1 / 2}<1
$$

The self-explanatory equations (Equation 7a-c), derived from the compressible flow theory, are highlighting herein for demonstrating the various influencing parameters and the conflicting requirements to prohibit the Sanal flow choking in the nanoscale fluid flow system. Equation 7a reveals that a disproportionate increase of the thermal conductivity of nanofluid increases the risk of Sanal flow choking leading to supersonic flow development followed by shock wave and pressure-overshoot in the nanoscale flow systems with sudden expansion or divergent region 
(Figure 1a-c). Therefore, the condition set by Equation 7a must be satisfied while addition nanomaterials in the base fluid for reducing the risk of catastrophic failure of nanoscale systems. Admittedly, in vitro parametric studies of nano scale aerospace propulsion systems in gravity and micro gravity conditions must be carried out with caution because, as disclosed by the closed-form analytical models, relatively high and low fluid viscosity are risk factors for the Sanal flow choking. Note that a significant decrease of fluid viscosity increases Reynolds number and turbulence level leading to an early Sanal flow choking due to the enhanced BLB factor. Viscosity variations are depending on the shear rate or shear rate history of the fluid, which could vary due to the variations in the thermophysical properties of nanomaterials and local effects too. It is important to note that while adding nanometer-sized materials to the base fluid the HCR of the nanofluid should not decrease. It aims for negating the undesirable Sanal flow choking phenomenon as it generates shock waves and inherent pressure-overshoot, which could alter the thermoviscoelastic properties of the vessel wall.

Note that in a vascular system the boundary layer induced flow choking leads to the shockwave generation and pressure-overshoot leading to memory effect, aneurysm, and hemorrhagic stroke as the case may be. This is a grey area in nano medicine, ${ }^{\mathbf{1 , 4 9 - 5 5}}$ which needs to be examined in detail through fluid-structural interactive multiphase, multispecies models, which is beyond the scope of this article. The Sanal flow choking for the diabatic condition presented herein is valid for all the real-world fluid flow problems for designing various nanoscale fluid flow systems and sub systems due to the fact that the model is untied from empiricism and any types of errors of discretization. Using Equation 1 and Equation 2 the chemical propulsion system designers could easily predict the likelihoods of detonation with the given inlet flow Mach number and the lowest value of the HCR of the leading gas coming from the upstream port of the chemical system. ${ }^{\mathbf{5 0}}$ In a 
nutshell, the best choice of increasing the solid fuel loading in the nanoscale thruster design without inviting any undesirable detonation and catastrophic failures, is to increase the HCR of the working fluid. Further discussion on the nanoscale propulsion system design is beyond the scope of this letter.

We have established herein that, due to the evolving boundary layer and the corresponding area blockage in the upstream port of any internal nanofluid flow system with sudden expansion or divergent region, the creeping diabatic nanoflow $\left(\mathrm{M}_{\mathrm{i}} \ll<1\right)$ originated from the upstream port of the system could accelerate to the supersonic flow leading to an undesirable phenomenon of pressure-overshoot due to shock wave generation as a result of the Sanal flow choking. Through the proposed mathematical methodology, we could disprove the general belief of the impossibilities of internal flow choking in such real-world nanoscale fluid flow systems at the creeping inflow conditions. There was a general belief in the scientific community over the centuries that the subsonic/creeping flow would not be augmented up to supersonic flow without passing through a geometric throat, which we have disproved herein through the closed-form analytical model. Note that if the total-to-static pressure ratio at the fluid-throat is lower than the LCDI the detonation would not occur even if the blockage factor is relatively high in nanoscale fluid flow systems. The physical insight of the Sanal flow choking and streamtube flow choking presented in this letter sheds light on finding solutions to numerous unresolved scientific problems carried forward over the centuries in physical, chemical and biological sciences.51-56 


\section{AUTHOR CONTRIBUTIONS}

VRSK: Conceptualization, analytical modeling, and in silico support, manuscript drafting; VS: Modeling and simulation support; NC: Modeling and simulation support, SARMR: analytical modeling support, AS: In silico simulation, PKR: Conceptualization and modeling support, SKC: Conceptualization and modeling support.

\section{FUNDING SOURCES}

The first author thanks to SERB/DST, the Government of India.

\section{NOTES}

The authors declare no competing financial interest.

\section{ACKNOWLEDGMENT}

Thanks to Science and Engineering Research Board (SERB) of the Department of Science and Technology (DST), the Government of India.
ABBREVIATIONS
3D-BLB, three-dimensional boundary-layer-blockage
$\mathrm{CD}$, convergent-divergent
CPR, critical pressure ratio
$\mathrm{C}_{\mathrm{p}}$, specific heat at constant pressure
DDT, deflagration to detonation transition
d, port diameter 
$\mathrm{d}_{\mathrm{H}}$, the hydraulic diameter of the duct

$\bar{f}$, average friction coefficient

HCR, heat capacity ratio

h, convective heat transfer coefficient

$K n$, Knudsen number

LCDI, lower critical detonation index

$l$, length of the upstream port

$\mathrm{L}^{*}$, port length up to the Sanal flow choking location

M, Mach number

Pr, Prandtl number

$\mathrm{P}_{\text {static }}$, static pressure

$\mathrm{Nu}$, Nusselt number

Re, Reynold number

s, entropy

$\mathrm{x}$, the characteristic length in the direction of growth of the boundary layer

$\gamma$, heat capacity ratio (HCR)

$\delta$, boundary layer displacement thickness

$\mu$, dynamic viscosity

$v$, kinematic viscosity

$\rho$, density 


\section{REFERENCES}

1. V.R.Sanal Kumar, Vigneshwaran Sankar, Nichith Chandrasekaran, Ajith Sukumaran, Sulthan Ariff Rahman Mohamed Rafic, Roshan Vignesh Baskaran, R.S.Bharath, Charlie Oommen, Pradeep Kumar Radhakrishnan, Shiv Kumar Choudhary, "Sanal Flow Choking: A Paradigm Shift in Computational Fluid Dynamics Code Verification and Diagnosing Detonation and Hemorrhage in Real-World Fluid-Flow Systems," Global Challenges, A Wiley $\quad$ Publication, $\quad$ May 2020, PMCID: $\underline{\text { PMC7267099, }}$ https://doi.org/10.1002/gch2.202000012

2. V.R. SanalKumar et al., "A closed-form analytical model for predicting 3D boundary layer displacement thickness for the validation of viscous flow solvers," AIP Advances, 8, 025315 (2018), pp.1-22, ; doi: 10.1063/1.5020333; https://doi.org/10.1063/1.5020333.

3. Whitby, M., Quirke, N. Fluid flow in carbon nanotubes and nanopipes. Nature Nanotech 2, 87-94 (2007). https://doi.org/10.1038/nnano.2006.175

4. The risks of nanomaterial risk assessment. Nature Nanotech. 15, 163 (2020). https://doi.org/10.1038/s41565-020-0658-9

5. Matsumoto, Y., Nichols, J. W., Toh, K., Nomoto, T., Cabral, H., Miura, Y., Kataoka, K. (2016). Vascular bursts enhance permeability of tumour blood vessels and improve nanoparticle delivery. Nature Nanotechnology, 11(6), 533538. doi:10.1038/nnano.2015.342

6. White, S., Geubelle, P. Get ready for repair-and-go. Nature Nanotech 5, 247-248 (2010). https://doi.org/10.1038/nnano.2010.66

7. Cingolani, R. The road ahead. Nature Nanotech 8, 792-793 (2013). https://doi.org/10.1038/nnano.2013.238 
8. Faria, M., Björnmalm, M., Thurecht, K.J. et al. Minimum information reporting in bionano experimental literature. Nature Nanotech 13,777-785 (2018). https://doi.org/10.1038/s41565-018-0246-4

9. Moscatelli, A. Nanoparticles go with the flow. Nature Nanotech (2013). https://doi.org/10.1038/nnano.2013.37

10. Toshiyuki Hayase, Numerical simulation of real-world flows, Fluid Dyn. Res. 47 (2015) 051201 (19pp), doi:10.1088/0169-5983/47/5/051201

11. Diez, F. J., Hernaiz, G., Miranda, J. J., \& Sureda, M. (2013). On the capabilities of nano electrokinetic thrusters for space propulsion. Acta Astronautica, 83, 97107. doi:10.1016/j.actaastro.2012.09.020

12. Borg, M. K., Lockerby, D. A., \& Reese, J. M. (2015). A hybrid molecular-continuum method for unsteady compressible multiscale flows. Journal of Fluid Mechanics, 768, 388414. doi:10.1017/jfm.2015.83

13. Wei Yu and Huaqing Xie, A Review on Nanofluids: Preparation, Stability Mechanisms, and Applications, Journal of Nanomaterials, Volume 2012, Article ID 435873, 17 pages doi:10.1155/2012/435873

14. Maxwell J C 1867 On the dynamical theory of gases Phil. Trans. R. Soc. 1574988

15. Abdelhamid Maali, Stéphane Colin, Bharat Bhushan. Slip length measurement of gas flow. Nanotechnology, Institute of Physics, 2016, 27 (37), pp.374004. 10.1088/09574484/27/37/374004, hal01392553

16. Majumder, M., Chopra, N., Andrews, R. \& Hinds, B. J. Nanoscale hydrodynamics: enhanced flow in carbon nanotubes. Nature 438, 44 (2005). 
17. Whitesides, G. M. (2006). The origins and the future of microfluidics. Nature, 442(7101), 368-373. doi:10.1038/nature05058

18. R. Qiao and N. R. Aluru, “'Charge inversion and flow reversal in a nanochannel electroosmotic flow", Physical Review Letters, Vol. 92, No. 19, Art. No. 198301, 14 May 2004.

19. Cooper, S. M., Cruden, B. A., Meyyappan, M., Raju, R., \& Roy, S. (2004). Gas Transport Characteristics through a Carbon Nanotubue. Nano Letters, 4(2), 377381. doi:10.1021/n10350682

20. Davarnejad, R., Barati, S. \& Kooshki, M. CFD simulation of the effect of particle size on the nanofluids convective heat transfer in the developed region in a circular tube. SpringerPlus 2, 192 (2013). https://doi.org/10.1186/2193-1801-2-192

21. A.Kamyar, R.Saidur, M.Hasanuzzaman, Application of Computational Fluid Dynamics (CFD) for nanofluids, International Journal of Heat and Mass Transfer, Volume 55, Issues 15-16, July 2012, $\quad$ Pages 4104-4115, https://doi.org/10.1016/j.ijheatmasstransfer.2012.03.052

22. Liu, J., Cheng, S., Cao, N. et al. Actinia-like multifunctional nanocoagulant for single-step removal of water contaminants. Nature Nanotech 14, 64-71 (2019). https://doi.org/10.1038/s41565-018-0307-8

23. Wei Yu and Huaqing Xie, A Review on Nanofluids: Preparation, Stability Mechanisms, and Applications, Journal of Nanomaterials, Volume 2012, Article ID 435873, 17 pages doi:10.1155/2012/435873

24. Frank J. Millero, Richard W. Curry, and Walter Drost-Hansen, Isothermal Compressibility of Water at Various Temperatures, Journal of Chemical and Engineering Data, Vol. 14, No. 4, October 1969, pp. 422-425, https://doi.org/10.1021/je60043a018 
25. Rana A. Fine and Frank J. Millero, Compressibility of Water as a Function of Temperature and Pressure, AIP The Journal of Chemical Physics, 59(10):5529-5536, November 1973, DOI: $10.1063 / 1.1679903$.

26. Brites, C., Xie, X., Debasu, M. et al. Instantaneous ballistic velocity of suspended Brownian nanocrystals measured by upconversion nanothermometry. Nature Nanotech 11, 851-856 (2016). https://doi.org/10.1038/nnano.2016.111

27. Khan, N.S., Shah, Q., Bhaumik, A. et al. Entropy generation in bioconvection nanofluid flow between two stretchable rotating disks. Sci Rep 10, 4448 (2020). https://doi.org/10.1038/s41598-020-61172-2

28. Tripathi, D., Bhushan, S., Bég, O.A. et al. Transient peristaltic diffusion of nanofluids: A model of micropumps in medical engineering. J Hydrodyn 30, 1001-1011 (2018). https://doi.org/10.1007/s42241-018-0140-4

29. HOYT, J. Laminar-turbulent transition in polymer solutions. Nature 270, 508-509 (1977). https://doi.org/10.1038/270508a0

30. Novère, N. L. et al. Minimum information requested in the annotation of biochemical models (MIRIAM). Nat. Biotechnol. 23, 1509-1515 (2005).

31. J. Buongiorno, Convective Transport in Nanofluids, J. Heat Transfer. Mar 2006, 128(3): 240-250 (11 pages) https://doi.org/10.1115/1.2150834

32. Holland, D. M., Borg, M. K., Lockerby, D. A., \& Reese, J. M. (2015). Enhancing nanoscale computational fluid dynamics with molecular pre-simulations: Unsteady problems and design optimisation. Computers \& Fluids, 115, 4653. doi:10.1016/j.compfluid.2015.03.023 
33. Murray, C. D. The physiological principle of minimum work. I. The vascular system and the cost of blood volume. Proc. Natl Acad. Sci. USA 12, 207-214 (1926).

34. McCulloh, K. A., Sperry, J. S., \& Adler, F. R. (2003). Water transport in plants obeys Murray's law. Nature, 421(6926), 939-942. doi:10.1038/nature01444

35. LaBarbera, M. Principles of design of fluid transport systems in zoology. Science $249,992-$ 999 (1990).

36. Jayagopal, A., Linton, M. F., Fazio, S., \& Haselton, F. R. (2010). Insights into Atherosclerosis Using Nanotechnology. Current Atherosclerosis Reports, 12(3), 209215. doi:10.1007/s11883-010-0106-7

37. Murugesan, S., Park, T.-J., Yang, H., Mousa, S., \& Linhardt, R. J. (2006). Blood Compatible Carbon Nanotubes - Nano-based Neoproteoglycans. Langmuir, 22(8), 34613463. doi:10.1021/la0534468

38. Patra, J. K., Das, G., Fraceto, L. F., Campos, E. V. R., Rodriguez-Torres, M. del P., AcostaTorres, L. S., et al., (2018). Nano based drug delivery systems: recent developments and future prospects. Journal of Nanobiotechnology, 16(1). doi:10.1186/s12951-018-0392-8

39. Singh, H., \& Myong, R. S. (2018). Critical Review of Fluid Flow Physics at Micro- to Nano-scale Porous Media Applications in the Energy Sector. Advances in Materials Science and Engineering, 2018, 1-31. doi:10.1155/2018/9565240

40. Holland, D. M., Borg, M. K., Lockerby, D. A., \& Reese, J. M. (2015). Enhancing nanoscale computational fluid dynamics with molecular pre-simulations: Unsteady problems and design optimisation. Computers \& $\quad$ Fluids, $115, \quad 46$ 53. doi:10.1016/j.compfluid.2015.03.023 
41. Chengxi Zhao, Duncan A. Lockerby, and James E. Sprittles, Dynamics of liquid nanothreads: Fluctuation-driven instability and rupture, Phys. Rev. Fluids 5, 044201 Published 2 April 2020.

42. Murray, C. D. The physiological principle of minimum work. I. The vascular system and the cost of blood volume. Proc. Natl Acad. Sci. USA 12, 207-214 (1926).

43. McCulloh, K. A., Sperry, J. S., \& Adler, F. R. (2003). Water transport in plants obeys Murray's law. Nature, 421(6926), 939-942. doi:10.1038/nature01444

44. LaBarbera, M. Principles of design of fluid transport systems in zoology. Science 249, 992999 (1990).

45. West, G. B., Brown, J. H. \& Enquist, B. J. A general model for the structure and allometry of plant vascular systems. Nature 400, 664-667 (1999).

46. Tao, T. Searching for singularities in the Navier-Stokes equations. Nat Rev Phys 1, 418419 (2019). https://doi.org/10.1038/s42254-019-0068-9

47. M. Moseler and U. Landman, Formation, stability, and breakup of nanojets, Science 289, 1165 (2000).

48. Anderson, J. Jr., "Modern Compressible Flow, with Historical Perspective,” Fourth Edition, McGraw-Hill Publishing Company, 2007

49. Lucas A. Lane, Physics in nanomedicine: Phenomena governing the in vivo performance of $\begin{array}{llll}\text { nanoparticles, } & \text { Applied } & \text { Physics } & \text { Reviews 7, }\end{array}$ (2020); https://doi.org/10.1063/1.5052455

50. V R Sanal Kumar et al., Deflagration to Detonation Transition in Chemical Rockets with Sudden Expansion / Divergence Regions, AIAA Propulsion and Energy 2020 Forum, 
Innovative Propulsion Concepts, August 24-28, 2020, AIAA 2020-3520, https://doi.org/10.2514/6.2020-3520

51. V.R.Sanal Kumar et al., "Lopsided Blood-thinning Drug Increases the Risk of Internal Flow Choking Leading to Shock Wave Generation Causing Asymptomatic Cardiovascular Disease," Global Challenges, A Wiley Publication, Vol.5, No.3, 2021, $10.1002 / \mathrm{gch} 2.202000076$

52. V.R.Sanal Kumar et al. Nanoscale Flow Choking and Spaceflight Effects on Cardiovascular Risk of Astronauts - A New Perspective, AIAA SciTech 2021, 11-15 Jan 2021, https://doi.org/10.2514/6.2021-0357

53. V.R.Sanal Kumar et al., Lopsided Blood-thinning Drug Increases The Risk Of Internal Flow Choking And Shock Wave Generation Causing Asymptomatic Stroke, International Stroke Conference, 17 March 2021, American Stroke Association (Published in Stroke Journal, https://doi.org/10.1161/str.52.suppl_1.P804, Stroke. 2021;52:AP804

54. V.R.Sanal Kumar et al., "Discovery of SANAL flow choking phenomenon," Patent Application No. 201841049355, Chennai, India, Date of online publication: January 4, 2019.

55. V.R.Sanal Kumar et al., Nanoscale Flow Choking in Cardiovascular System: In vitro prediction of the lower / upper-critical-hemorrhage-index, Nature Neuroscience (Under review).

56. V.R.Sanal Kumar et al., The Theoretical Prediction of the Boundary layer Blockage and External Flow Choking at Moving Aircraft in Ground Effects, Physics of Fluids, Vol.33, No.3, 2021, DOI: 10.1063/5.0040440 


\section{Competing Interests: None}

Authors have no competing interests as defined by your publications or other interests that might be perceived to influence the results and/or discussion reported in this paper.

Data and materials availability:

All data needed to evaluate the conclusions of the paper are available in the manuscript.

Disclosure Statement of Authors: Nothing to disclose

Declarations of interest: None

Disclosure Statement of Authors: Nothing to disclose 
Figures
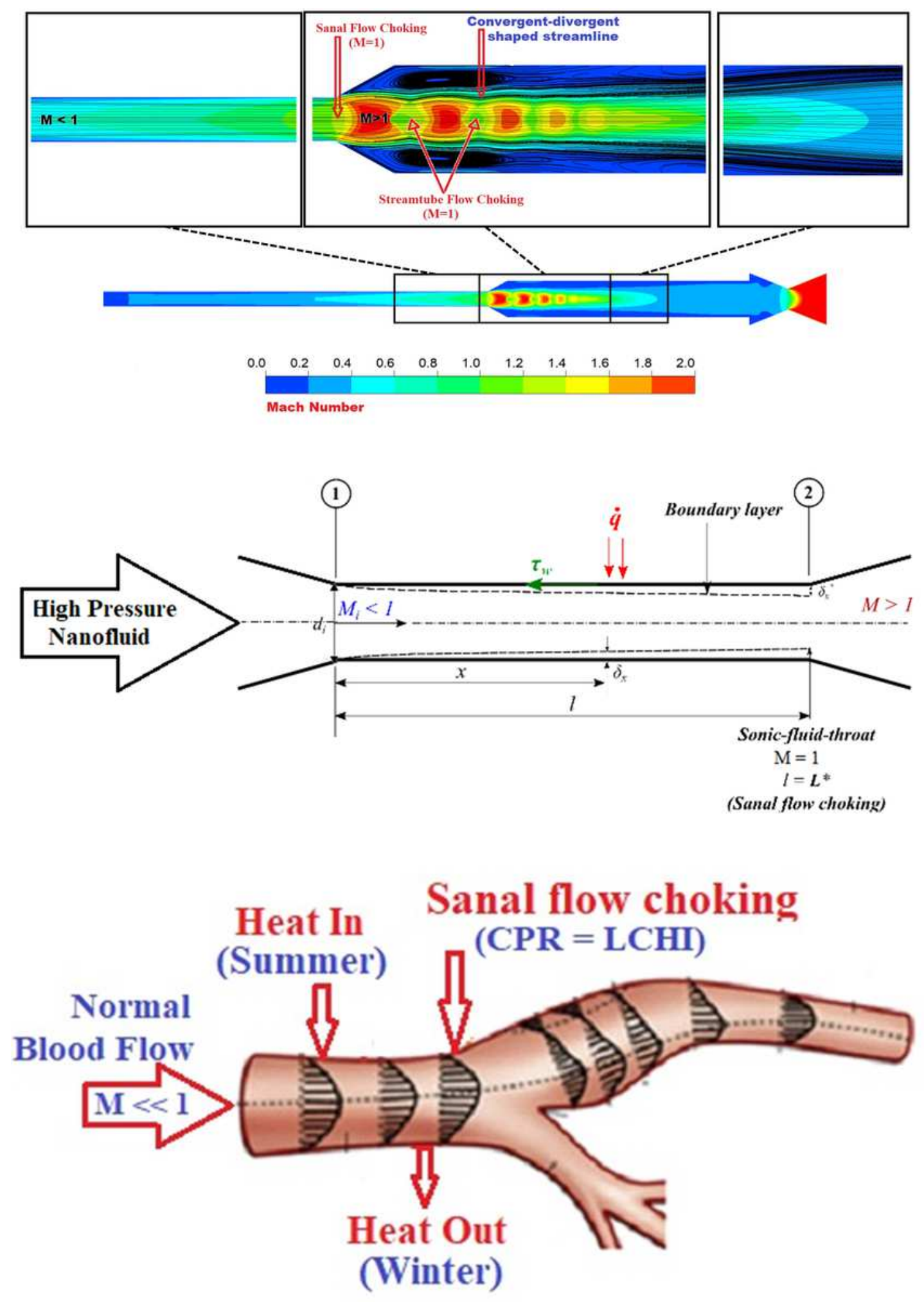

Figure 1

a. The enlarged view of the Sanal flow choking and the streamtube flow choking phenomena in an idealized physical model of an internal fluid flow system <Movie: https://youtu.be/bv3ZDcPKMSI>. b. Demonstrating the Sanal flow choking condition in an idealized physical model of an internal nanoscale 
fluid flow system. c. Seasonal variations and the Sanal flow choking in an artery with bifurcation and without any plaque
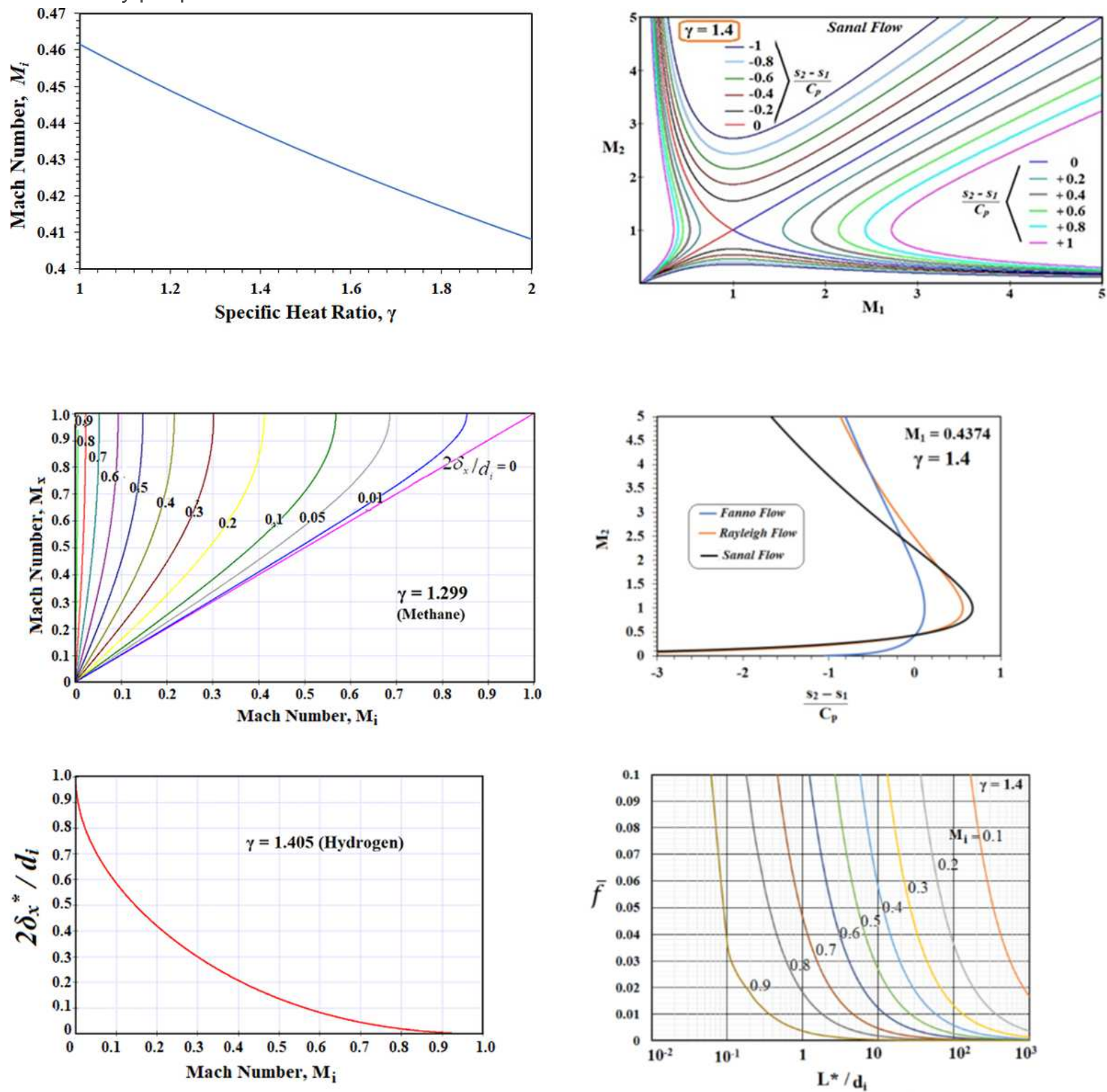

Figure 2

a. The inlet Mach number prediction of different gases with different HCR ( $\mathrm{Y}$ ) for achieving Sanal flow choking condition for diabatic nano scale flows. b. The solution curve of Equation $2 a$ is showing the 3D blockage factor with Methane as the working fluid. c. The solution curve of Equation $2 b$ is showing the 3D blockage factor in the sonic-fluid-throat of a nano scale fluid flow system with hydrogen as the working fluid. $d$. The demonstration of the Sanal flow choking in diabatic nano scale fluid flows. (Solution 
curves of Equation 4). e. Mach Number-Entropy chart of Fanno, Rayleigh and Sanal flow models at the choked flow condition. $f$. Analytical predictions of the average friction coefficient at the Sanal flow choking condition of different nanotubes at different inlet conditions. 